\title{
BMJ
}

\section{Effect of school based physical activity programme(KISS) on fitness and adiposity in primary schoolchildren: cluster randomised controlled trial}

\author{
Susi Kriemler, assistant professor for pediatric sports medicine, ${ }^{1,3}$ Lukas Zahner, postdoctoral research \\ fellow, ${ }^{1,2}$ Christian Schindler, statistician, ${ }^{3}$ Ursina Meyer, research assistant, ${ }^{1}$ Tim Hartmann, research \\ assistant, ${ }^{1}$ Helge Hebestreit, professor of pediatric pulmonology, ${ }^{4}$ Hans Peter Brunner-La Rocca, professor of \\ cardiology, ${ }^{5}$ Willem van Mechelen, professor of occupational and sports medicine, ${ }^{6}$ Jardena J Puder, assistant \\ professor of endocrinology, diabetes and metabolism ${ }^{7}$
}

\section{ABSTRACT}

stitute of Exercise and Health Sciences, University of Basel, 4052 Basel, Switzerland

${ }^{2}$ Swiss Federal Office of Sports, 2532 Magglingen, Switzerland

${ }^{3}$ Swiss Tropical and Public Health Institute, University of Basel

${ }^{4}$ University Children's Hospital, 97080 Wuerzburg, Germany

${ }^{5}$ Medical University Center Maastricht, Cardiology, 6202 Maastricht, Netherlands

${ }^{6}$ Department of Public and Occupational Health and EM

GO Institute, VU University

Medical Center, 1081 Amsterdam, Netherlands

${ }^{7}$ Service of Endocrinology, Diabetes and Metabolism, University of Lausanne, 1011 Lausanne, Switzerland

Correspondence to: S Kriemler susi.kriemler@unibas.ch

Cite this as: BMJ 2010;340:c785 doi:10.1136/bmj.c785
Objective To assess the effectiveness of a school based physical activity programme during one school year on physical and psychological health in young schoolchildren.

Design Cluster randomised controlled trial.

Setting 28 classes from 15 elementary schools in

Switzerland randomly selected and assigned in a 4:3 ratio to an intervention $(n=16)$ or control arm $(n=12)$ after stratification for grade (first and fifth grade), from August 2005 to June 2006.

Participants 540 children, of whom 502 consented and presented at baseline.

Intervention Children in the intervention arm $(n=297)$ received a multi-component physical activity programme that included structuring the three existing physical education lessons each week and adding two additional lessons a week, daily short activity breaks, and physical activity homework. Children $(n=205)$ and parents in the control group were not informed of an intervention group. For most outcome measures, the assessors were blinded. Main outcome measures Primary outcome measures included body fat (sum of four skinfolds), aerobic fitness (shuttle run test), physical activity (accelerometry), and quality of life (questionnaires). Secondary outcome measures included body mass index and cardiovascular risk score (average $z$ score of waist circumference, mean blood pressure, blood glucose, inverted high density lipoprotein cholesterol, and triglycerides).

Results 498 children completed the baseline and followup assessments (mean age 6.9 (SD 0.3) years for first grade, 11.1 (0.5) years for fifth grade). After adjustment for grade, sex, baseline values, and clustering within classes, children in the intervention arm compared with controls showed more negative changes in the z score of the sum of four skinfolds $(-0.12,95 \%$ confidence interval -0.21 to $-0.03 ; P=0.009)$. Likewise, their $z$ scores for aerobic fitness increased more favourably $(0.17,0.01$ to 0.32; $P=0.04)$, as did those for moderate-vigorous physical activity in school $(1.19,0.78$ to $1.60 ; \mathrm{P}<0.001)$, all day moderate-vigorous physical activity $(0.44,0.05$ to $0.82 ; \mathrm{P}=0.03)$, and total physical activity in school $(0.92$, 0.35 to $1.50 ; \mathrm{P}=0.003)$. $Z$ scores for overall daily physical activity $(0.21,-0.21$ to 0.63$)$ and physical quality of life $(0.42,-1.23$ to 2.06$)$ as well as psychological quality of life $(0.59,-0.85$ to 2.03$)$ did not change significantly. Conclusions A school based multi-component physical activity intervention including compulsory elements improved physical activity and fitness and reduced adiposity in children.

Trial registration Current Controlled Trials ISRCTN15360785.

\section{INTRODUCTION}

One in three to five children in the Western world is overweight or obese. ${ }^{1}$ This epidemic is rapidly and constantly growing and affects all socioeconomic levels and ethnicities. ${ }^{2}$ Excessive weight is associated with increased cardiovascular risk, ${ }^{3}$ orthopaedic problems, and psychosocial constraints even before adulthood is reached. ${ }^{4}$ Life expectancy may be reduced by several years, ${ }^{5}$ as is work productivity, while costs are increasing enormously. A focus on early prevention is thus urgently needed.

The increase in physical inactivity over the past decades is one of the main causes of the increase in obesity. ${ }^{6}$ In adults, physical inactivity and low aerobic fitness are associated with higher mortality and a higher prevalence of chronic disease. ${ }^{7}$ In children, physical inactivity and lack of fitness are associated with increasing prevalence of cardiovascular risk factors, ${ }^{38}$ even independent of body weight. ${ }^{9}$

As obesity, cardiovascular risk factors, and risk behaviour usually change little from childhood to adulthood, ${ }^{1011}$ promotion of positive health related behaviour in early life is important and expected to have long term benefits. However, studies of school based interventions promoting a healthy lifestyle have shown disappointing results, ${ }^{1213}$ and these trials have often had important methodological or conceptual 
limitations that should be overcome in future research. ${ }^{14}$ A theory driven, randomised, controlled physical activity intervention in youth with a global assessment of cardiovascular risk factors is still lacking.

Our goal was to intervene at the level of the school class, so we did a cluster randomised controlled trial with a school based stringent physical activity programme versus traditional physical education during one school year. We aimed to increase aerobic fitness, physical activity, and quality of life while decreasing body fat and a composite cardiovascular risk factor score in the intervention group compared with the control group.

\section{METHODS}

Design and study population

The study took place in two of the 26 provinces of Switzerland (Aargau and Baselland), comprising about $10 \%$ of the Swiss population. Recruitment started in autumn 2004, and the actual study took place between August 2005 and July 2006. The design of the study has been previously described in detail, ${ }^{15}$ and figure 1 describes the selection process. We selected 28 of 190 consenting classes on the basis of a computer generated random number table that was in the hands of a person not involved in the study. Participating schools fulfilled our eligibility criteria: rural or urban localisation, a prevalence of $10-30 \%$ migrants as in the Swiss population, and, for practical reasons, the presence of at least a first grade and a fifth grade class in each school (fig 1). Intervention and control schools were located in provinces that were comparable as regards socioeconomic status of the population and recreational facilities at school. To avoid contamination of treatments, we randomised by school. However, the school director had no role during the whole study period, and all parts of the intervention were done at the class level. Classes from the intervention and control groups were located in different villages or towns. All participating children and their parents gave informed consent.

\section{Intervention}

The intervention was targeted at both the cluster and the individual level and was based on a socio-ecological conceptual model focusing on increasing daily physical activity, ${ }^{16}$ as described previously and in figure $2 .{ }^{15}$ Briefly, children in both groups had three physical education lessons each week, which are compulsory by law. The intervention group had two additional physical education lessons on the remaining school days. A team of expert physical education teachers prepared all five physical education lessons for the children in the intervention group. All intervention classes received the same curriculum. The three compulsory weekly physical education lessons (45 minutes each) were given by the usual classroom teachers according to the specified curriculum, whereas the two additional weekly lessons (45 minutes each) were taught mostly outdoors by physical education teachers. In addition, three to five short activity breaks (two to five minutes each) during academic lessons - comprising motor skill tasks such as jumping or balancing on one leg, power games, or coordinative tasks - were introduced every day. The children received daily physical activity homework of about 10 minutes' duration prepared by the physical education teachers. This included aerobic, strength, or motor skill tasks such as brushing their teeth while standing on one leg, hopping up and down the stairs, rope jumping, or comparable activities. Children and parents in the control group were not informed about the existence of the intervention programme in other schools. The teachers in the control group knew about the intervention arm but were not informed about its content. No incentives for participating in the study were offered to the children.

\section{Outcome measures}

Baseline (August 2005) and follow-up (June 2006) measurements took place at school within the same three week period for all children; the intervention period lasted nine months. All assessors were trained in a pilot study two months before the main study. Assessors responsible for the measurements were blinded to the group allocation for all measurements except skinfold and waist circumference measures. School laws prescribed that the last two measurements were made by designated physicians who knew the group allocation. Outcome measures are reported at the individual level. Primary outcome measures included the sum of four skinfolds, aerobic fitness, physical activity, and quality of life. Secondary outcome measures included

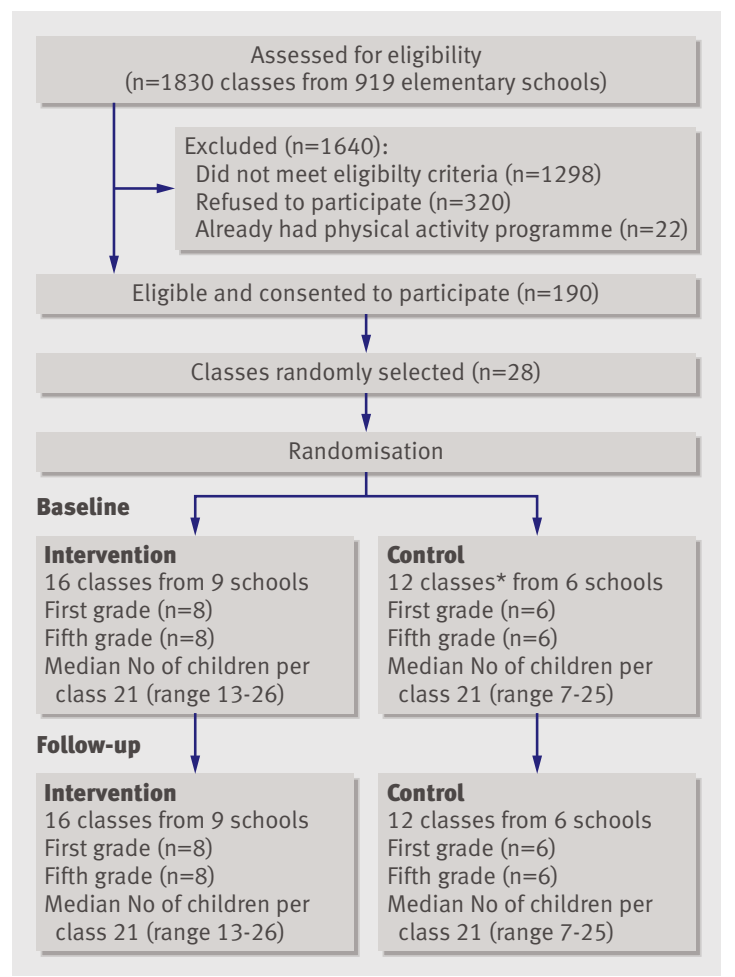

Fig 1| Flow of school classes through study (study cluster). *Contrary to protocol, ${ }^{15}$ in which one control class was misclassified, 12 (not 11) classes were randomised to control group 


\begin{tabular}{|c|c|c|}
\hline \multirow{2}{*}{$\begin{array}{l}\text { Baseline } \\
\text { measurements }\end{array}$} & Intervention group & \multirow{5}{*}{$\begin{array}{l}\text { Follow-up } \\
\text { measurements } \\
\text { At school: } \\
2 \text { hours' fitness testing } \\
2 \text { hours' medical testing } \\
5 \text { days' accelerometry }\end{array}$} \\
\hline & $2 \times 45 \mathrm{~min} /$ week: physical education lessons given by physical education teacher & \\
\hline \multirow{3}{*}{$\begin{array}{l}\text { At school: } \\
2 \text { hours' fitness testing } \\
2 \text { hours' medical testing } \\
5 \text { days' accelerometry }\end{array}$} & $3 \times 45 \mathrm{~min} /$ week: physical education lessons given by classroom teacher & \\
\hline & Several 5 minute bouts per day: short physical activity breaks & \\
\hline & $10 \mathrm{~min} /$ day: physical activity homework & \\
\hline \multirow{2}{*}{$\begin{array}{l}\text { At home: } \\
\text { questionnaires }\end{array}$} & Control group & \multirow{3}{*}{$\begin{array}{l}\text { At home: } \\
\text { questionnaires } \\
3 \text { weeks }\end{array}$} \\
\hline & $3 \times 45 \mathrm{~min} /$ week: physical education lessons given by classroom teacher & \\
\hline 3 weeks & & \\
\hline \multirow[b]{2}{*}{$\begin{array}{l}\text { Start of school year } \\
\quad \text { (August 2005) }\end{array}$} & $\begin{array}{l}\text { Intervention period: } 9 \text { months } \\
\text { (including period of follow-up measurements) }\end{array}$ & \\
\hline & & $\begin{array}{l}\text { End of school year } \\
\text { (July 2006) }\end{array}$ \\
\hline
\end{tabular}

Fig 2 | Content and timetable of intervention

body mass index and a cardiovascular risk score comprising all components of the metabolic syndrome. Additional predefined secondary outcomes such as bone mineral content and bone density, as well as bone turnover markers and calcium intake, will be reported separately.

We calculated the percentage of overweight children on the basis of Swiss national centiles. ${ }^{17}$ Skinfold thickness was measured in triplicate to the nearest $0.5 \mathrm{~mm}$ with Harpenden calipers (HSK-BI, British Indicators). We calculated the sum of four sites (triceps, biceps, subscapular, and suprailiacal). ${ }^{18}$ We used the $20 \mathrm{~m}$ shuttle run test to determine aerobic fitness. ${ }^{19}$ Ten children did the test together, but each child had a researcher assigned who was checking adequate test procedures. We monitored physical activity with an accelerometer (MTI/CSA 7164, Actigraph, Shalimar, FL, USA), which was worn continuously around the hip for five weekdays, at baseline and at the end of the intervention. We set the sampling epoch to one minute. We omitted time periods with more than 15 minutes of continuous zero values. We included an individual child's physical activity data if at least two weekdays of measurements with a minimum of 12 hours were recorded. ${ }^{20}$ In addition, weekdays had to include at least one physical education lesson. In case of missing data (measurement of less than five days), we averaged the number of days with and without physical education separately and, on the basis of the class schedule, extrapolated them to a school week of five days. Eighty-nine per cent of all children had three to five monitoring days on both occasions, $11 \%$ had two monitoring days (that is, 6.8\% imputed days), which is sufficient to be representative of the school week, ${ }^{8}$ especially as the amount of physical activity among the single school days did not differ. ${ }^{21}$ At baseline, the number of missed measurement days with and without physical education did not differ between the groups. We expressed physical activity as average counts/minute and moderate-vigorous physical activity as minutes above 2000 counts/minute (which is equivalent to walking at about $4 \mathrm{~km}$ /hour) for the whole day, the time in school, and the time out of school. We assessed quality of life with the child health questionnaire, ${ }^{22}$ distributed at school in coded envelopes and completed by the child, with the help of the parents if necessary.

We measured blood pressure in the right arm five times after a resting period of five minutes by using an automated oscillograph (Oscillomate, CAS Medical Systems, Branford, CT, USA). We took the mean of the three measurements with the smallest variation and then $\mathrm{z}$ transformed it. ${ }^{23}$ Blood was drawn in the morning while the child was fasting for measurement of glucose and lipids as previously described. ${ }^{15}$ Although not specified in the paper describing the study design, we computed a composite cardiovascular risk score by averaging the $\mathrm{z}$ scores of all components of the metabolic syndrome (waist circumference, blood pressure (mean of systolic and diastolic blood pressure z score), glucose, inverted high density lipoprotein cholesterol, and triglycerides). ${ }^{24} \mathrm{We}$ log transformed skewed data. We derived $\mathrm{z}$ scores from published age and sex specific norm values for body mass index and blood pressure. ${ }^{2325}$ We $\mathrm{z}$ transformed the remaining variables by using grade and sex specific means and standard deviations derived from the whole sample for the baseline measurements and from the control sample for the post-intervention measurements. At the end of the study, we asked children and teachers of the intervention group about their enjoyment of the programme and whether they wanted the programme to continue in the future by using a six point scale ranging from 1 (very much) to 6 (not at all).

\section{Statistical analysis}

We based statistical analyses on the intention to treat principle and report results at the level of individual children. We used a regression model with adjustment for cluster to compare baseline measurements of the two groups. As the study population consisted of two distinct age groups, all analyses estimating effects of the intervention on outcomes used $\mathrm{z}$ scores based on grade and sex. We used mixed linear models with z scores at follow-up as dependent variables; group, sex, and grade as fixed factors; school class as a random effect; and the respective baseline $\mathrm{z}$ score as a covariate. School class was the smallest cluster in the sampling 


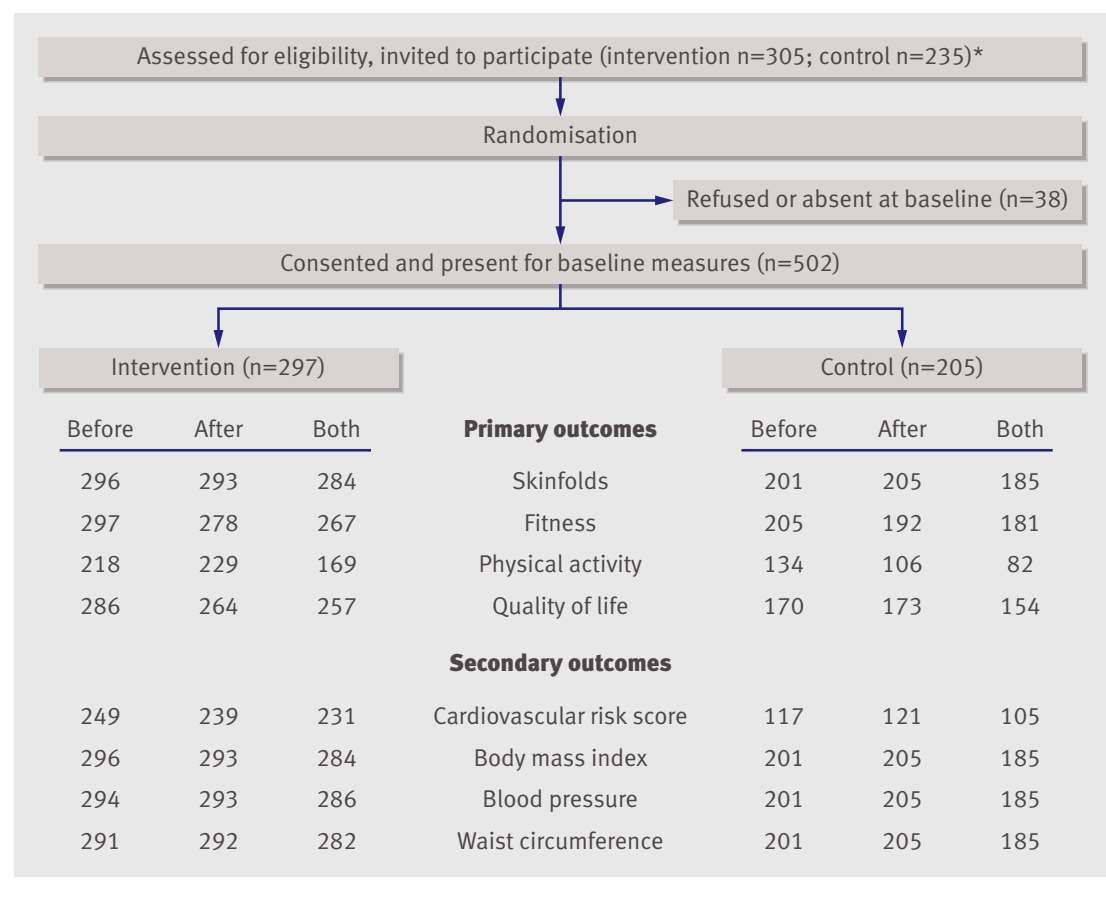

Fig 3 | Flow of individual participants through study, with outcome measures. *Contrary to protocol, ${ }^{15} 28$ (not 27) classes were randomised, 16 classes with 305 (not 300) to intervention group and 12 (not 11) classes with 205 children to control group; furthermore, one child was misclassified as in intervention instead of control group

design, so we introduced it as a random effect. We calculated the intraclass correlation to compare the variation between school classes as a fraction of the total variance. We also tested whether the additional cluster "school" influenced the results. We did not include pubertal stage according to Tanner stage, migrant status, or socioeconomic status as covariates, as their addition to the model did not change the results. For each outcome measure, we report the size of the intervention effect as the difference in its average $\mathrm{z}$ scores at follow-up between the intervention and control groups after adjustment for grade, sex, baseline values, and clustering within school classes. We did secondary analyses by testing interactions of the intervention with sex, grade, and baseline body mass index, categorised into two groups above and below the median..$^{25}$

We based our sample size calculation on a predefined ratio of $4: 3$ between intervention and control schools each contributing two classes of 20 children.
The study was powered to detect a medium effect size on the primary study outcome measures of 0.5 units of standard deviation with $79 \%$ probability if the intraclass correlation coefficient within schools was 0.10 and with $90 \%$ probability for a coefficient of 0.06 for each primary outcome measure. The sample size needed to reach the estimated power was a total of 360 children at the third measurement, four years after the baseline assessment. Assuming an attrition rate of $10-15 \%$ and accounting for the multiple secondary outcomes, we recruited 540 children to provide adequate power to test the null hypothesis of the intervention having no effect for each of the primary outcomes.

\section{RESULTS}

Twenty-eight classes in 15 schools totalling 540 children entered the study. Figures 1 and 3 give sample size information throughout the trial. Table 1 shows the baseline characteristics stratified by allocation arm and grade. Tables 2 and 3 describe primary and secondary outcomes at baseline and follow-up. No significant differences existed between the groups at baseline. This is also true for the $\mathrm{z}$ scores of total physical activity in school, which were 0.01 (SD 0.99) for the children in the intervention group and -0.02 (SD1.02) for those in the control group ( $\mathrm{P}=0.76)$. Moreover, children with a baseline assessment but no follow-up assessment did not differ from the remaining children in terms of age, sex, and the primary and secondary outcome variables at baseline (data not shown).

\section{Primary outcomes}

Table 2 shows the results of the primary outcomes at baseline and follow-up, as well as the adjusted differences at follow-up. Compared with controls, children in the intervention group showed smaller increases in the sum of four skinfolds by $0.12(95 \%$ confidence interval -0.21 to -0.03$)$ z score units, corresponding to about $2 \mathrm{~mm}$ (or $6 \%$ of the mean baseline value). Four control children and five intervention children were underweight (below the third centile for weight) at baseline; the prevalence of underweight did not increase in either group. The intervention increased children's aerobic fitness by $0.17(0.01$ to 0.32$) \mathrm{z}$ score units, representing an improvement of $5 \%$ of mean baseline values. This effect corresponds to an

Table 1|Baseline characteristics of 502 elementary schoolchildren according to treatment arm and grade. Values are numbers (percentages) unless stated otherwise

\begin{tabular}{|c|c|c|c|c|}
\hline & \multicolumn{2}{|c|}{ First grade } & \multicolumn{2}{|c|}{ Fifth grade } \\
\hline & Intervention $(\mathrm{n}=131)$ & Control $(n=91)$ & Intervention $(n=166)$ & Control $(n=114)$ \\
\hline Girls & 64 (49) & $50(55)$ & $91(55)$ & $52(46)$ \\
\hline Mean (SD) age (years) & $6.9(0.3)$ & $6.9(0.3)$ & $11.0(0.5)$ & $11.3(0.6)$ \\
\hline Overweight* & $34(26)$ & $26(29)$ & $41(25)$ & $28(25)$ \\
\hline Tanner stage $>1$ & 0 & 0 & $83(50)$ & $54(48)$ \\
\hline Migrant families† & $45(34)$ & $23(26)$ & $41(25)$ & $27(24)$ \\
\hline No formal parental education & $12(9)$ & $4(5)$ & $19(12)$ & $12(11)$ \\
\hline
\end{tabular}

*Based on Swiss national centiles.

†Both parents from Eastern or Southern European countries, Africa, Asia, Central or South America, or other less developed countries. 
Table 2|Primary outcome measures in children according to physical activity intervention aimed at increasing physical activity and fitness and at reducing body fat and cardiovascular risk score. Values are mean (SD) unless stated otherwise

\begin{tabular}{|c|c|c|c|c|c|c|c|}
\hline \multirow[b]{2}{*}{ Variables } & \multicolumn{2}{|c|}{ Intervention $(n=297)$} & \multicolumn{2}{|c|}{ Control $(n=205)$} & \multicolumn{3}{|c|}{ Adjusted difference at follow-up* } \\
\hline & Before & After & Before & After & Coefficient $(95 \% \mathrm{Cl})$ & $P$ value & ICC \\
\hline Skinfolds (mm) & $32.11(13.23)$ & $32.50(14.67)$ & $31.32(12.82)$ & $33.70(17.24)$ & $-0.12(-0.21$ to -0.03$)$ & 0.009 & 0.06 \\
\hline Shuttle run (stages) & $5.6(2.3)$ & $6.8(2.2)$ & $5.8(2.1)$ & $6.7(1.9)$ & $0.17(0.01$ to 0.32$)$ & 0.04 & 0.03 \\
\hline Total physical activity (counts/min) & 770 (197) & $726(181)$ & $792(204)$ & $728(225)$ & $0.21(-0.21$ to 0.63$)$ & 0.31 & 0.15 \\
\hline In school & $807(276)$ & $870(217)$ & $828(292)$ & $738(235)$ & $0.92(0.35$ to 1.50$)$ & 0.003 & 0.24 \\
\hline Out of school & $755(217)$ & $653(197)$ & 777 (209) & $722(248)$ & $-0.14(-0.51$ to 0.22$)$ & 0.41 & 0.09 \\
\hline Total MVPA (min/day) & $106(36)$ & $106(34)$ & $106(33)$ & $97(34)$ & $0.44(0.05$ to 0.82$)$ & 0.03 & 0.08 \\
\hline In school & $38(16)$ & $45(14)$ & $37(14)$ & $32(12)$ & $1.19(0.78$ to 1.60$)$ & $<0.001$ & 0.11 \\
\hline Out of school & $67(27)$ & $61(25)$ & $69(25)$ & $66(28)$ & $-0.06(-0.39$ to 0.27$)$ & 0.72 & 0.06 \\
\hline Physical quality of life & $53.4(8.9)$ & $53.7(8.7)$ & $53.2(7.7)$ & $53.9(6.5)$ & $0.42(-1.23$ to 2.06$)$ & 0.62 & 0.00 \\
\hline Psychological quality of life & $52.5(6.9)$ & $52.3(7.7)$ & $53.0(6.5)$ & $52.0(7.3)$ & $0.59(-0.85$ to 2.03$)$ & 0.42 & 0.02 \\
\hline
\end{tabular}

$\mathrm{ICC}=$ intraclass correlation coefficient; MVPA=moderate and vigorous physical activity.

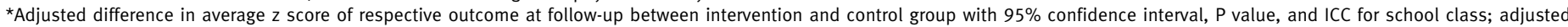
for grade, sex, and $z$ score at baseline in mixed linear model with random effect for school class.

increase in running time of 20 seconds. The change in moderate-vigorous physical activity from baseline to follow-up was significantly higher in the intervention group: the difference in average $\mathrm{z}$ score for in-school activity was 1.19 (0.78 to 1.60$)$, corresponding to about 13 additional minutes, and that for all day activity was 0.44 ( 0.04 to 0.82 ), corresponding to 11 additional minutes. Likewise, the change in total physical activity in school was higher in the intervention group than in the control group, corresponding to a relative increase of $18 \%$ - that is, a shift of the median to the 82 nd centile. However, the change in overall daily physical activity from baseline to follow-up showed only a non-significant trend in favour of the intervention group.

Effects of the intervention on primary outcomes were comparable in children with and without complete physical activity data (all $\mathrm{P}>0.3$ ). Quality of life did not change in the two groups. The intraclass correlations were $\leq 0.1$, indicating a low level of clustering within school classes, except for total physical activity for which the coefficient was larger (0.09-0.24). An additional adjustment of all primary outcome analyses for the random effect of "school" showed no further variance for those primary outcomes that were significantly improved by the intervention. The factor "school" had an effect only on physical quality of life, for which it explained $2 \%$ of the residual variance.

\section{Secondary outcomes}

Table 3 shows the baseline and follow-up data and the adjusted differences at follow-up for cardiovascular risk factors in both groups. Children in the intervention group showed smaller increases or larger reductions in body mass index and in most cardiovascular risk factors such as triglycerides, high density lipoprotein cholesterol, and glucose. The cardiovascular risk score decreased more in the intervention than in the control group, corresponding to $0.18(-0.29$ to -0.06$) \mathrm{z}$ score units and representing a shift from the median to the 36 th centile (that is, 14\%). This finding remained unchanged when we standardised waist circumference on the basis of a reference population or when we replaced waist circumference by body mass index z scores. ${ }^{2526}$ Secondary analyses also involved the study of potential modifications of the effect by sex, grade, or baseline body mass index (dichotomised at the median). ${ }^{25}$ The intervention by grade interaction

Table $3 \mid$ Secondary outcome measures in children according to physical activity intervention aimed at increasing physical activity and fitness and at reducing body fat and cardiovascular risk score*. Values are mean (SD) unless stated otherwise

\begin{tabular}{|c|c|c|c|c|c|c|c|}
\hline & \multicolumn{2}{|c|}{ Intervention $(n=297)$} & \multicolumn{2}{|c|}{ Control $(n=205)$} & \multicolumn{3}{|c|}{ Adjusted difference at follow-up $\dagger$} \\
\hline & Before & After & Before & After & $95 \% \mathrm{Cl}$ & $P$ value & ICC \\
\hline Cardiovascular risk score & $0.01(0.49)$ & $-0.27(0.44)$ & $0.06(0.53)$ & $-0.03(0.51)$ & $-0.18(-0.29$ to -0.06$)$ & 0.003 & 0.06 \\
\hline Body mass index $\left(\mathrm{kg} / \mathrm{m}^{2}\right)$ & $17.13(2.53)$ & $17.36(2.67)$ & $17.04(2.63)$ & $17.44(2.89)$ & $-0.12(-0.19$ to -0.04$)$ & 0.003 & 0.01 \\
\hline Waist circumference $(\mathrm{cm})$ & $57.95(6.94)$ & $59.45(6.87)$ & $57.66(6.43)$ & $59.86(7.39)$ & $-0.08(-0.2$ to 0.05$)$ & 0.25 & 0.17 \\
\hline Systolic blood pressure $(\mathrm{mm} \mathrm{Hg})$ & $104(9)$ & $101(9)$ & $103(8)$ & $102(9)$ & $-0.08(-0.26$ to 0.23$)$ & 0.88 & 0.19 \\
\hline Diastolic blood pressure $(\mathrm{mm} \mathrm{Hg})$ & $62(8)$ & $60(7)$ & $61(7)$ & $61(8)$ & $-0.12(-0.35$ to 0.10$)$ & 0.28 & 0.20 \\
\hline Triglycerides (mmol/l) & $0.60(0.25)$ & $0.60(0.25)$ & $0.64(0.29)$ & $0.69(0.32)$ & $-0.10(-0.18$ to -0.01$)$ & 0.02 & 0.00 \\
\hline HDL cholesterol (mmol/l) & $1.65(0.35)$ & $1.68(0.35)$ & $1.60(0.35)$ & $1.55(0.37)$ & 0.27 (0.09 to 0.44$)$ & 0.003 & 0.05 \\
\hline Glucose (mmol/l) & $4.5(0.4)$ & $4.6(0.3)$ & $4.6(0.4)$ & $4.7(0.4)$ & $-0.40(-0.70$ to -0.09$)$ & 0.01 & 0.10 \\
\hline
\end{tabular}

$\mathrm{HDL}=$ high density lipoprotein; ICC=intraclass correlation coefficient.

*Average z score of waist circumference, mean of systolic and diastolic blood pressure z score, glucose, triglycerides, and inverse HDL-cholesterol.

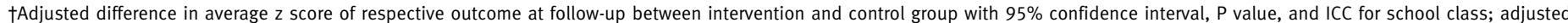
for grade, sex, and $z$ score at baseline in mixed linear model with random effect for school class. 
was significant for the sum of four skinfolds ( $\mathrm{P}=0.003)$, with a stronger intervention effect in fifth grade children. All other interactions had $\mathrm{P}$ values larger than 0.1 . Ninety per cent of the children and $70 \%$ of the teachers in the intervention group enjoyed the five physical education lessons and wanted them to continue in future years (scores of 1-2 for children and 13 for teachers on a six point scale).

\section{DISCUSSION}

This randomised controlled trial showed that a multicomponent physical activity intervention for one school year in first and fifth grade schoolchildren favourably affected body composition, aerobic fitness, physical activity, and cardiovascular risk.

Our programme resulted in a relative decrease (that is, a lesser increase) in body fat in the intervention group compared with the control group. These findings were consistent for body mass index and skinfold thickness. The favourable changes in body composition occurred in children across the whole range of body mass index and did not increase the number of underweight children. Establishing a programme with consistent positive effects on body composition is of major public health importance; in well designed reviews, only very few lifestyle or physical activity intervention programmes were considered effective in reducing body fat or body mass index in schoolchildren. ${ }^{1327}$ The absolute effect of our intervention on body fat seems small, with a difference in skinfold thickness of about $2 \mathrm{~mm}$ between children in the intervention and control groups. However, this corresponds to $6 \%$ of the average baseline value and it was achieved within less than one year in otherwise healthy children. The effect is similar to that in a few comparable intervention studies but is higher than that in most other studies. ${ }^{1328}$ This is an important result for public health, as a higher body mass index in childhood, even in the absence of overt overweight, has been associated with coronary heart disease in adulthood. ${ }^{29}$ In addition, a higher body mass index in adolescence predicted adverse health effects in adults even in the absence of obesity in adulthood. ${ }^{30}$

The intervention also led to an increase in aerobic fitness. This effect corresponds to a difference in running time of 20 seconds or a difference in the covered distance of 60 metres equivalent to an average increase of $5 \%$ from baseline, which is substantial considering the worldwide decline of youth fitness by $0.43 \%$ a year over the past two decades. ${ }^{31}$ Only one previous controlled intervention trial found improvements in body composition and in aerobic fitness. ${ }^{32}$ Additionally, our intervention resulted in an improved cardiovascular risk score that included all components of the metabolic syndrome. This reduction in cardiovascular risk occurred in all children in the intervention group, irrespective of their initial body mass index z scores. To our knowledge, this is the first study of a school based, long term physical activity intervention that documents beneficial changes in all these parameters. Our study was a demanding "real life" intervention trial, in which we successfully increased physical activity, thereby achieving multiple beneficial health effects. As not only obesity but also the presence of overt cardiovascular disease is seen in an increasing number of children, ${ }^{33}$ a shift of the population median by five to seven points in the favourable direction on the centile scale as documented in our intervention group for body fat and fitness and for the cardiovascular risk score would be expected to have a considerable impact on public health. ${ }^{34}$ Moreover, the observed effects at the group level were large enough to be relevant even at the individual level.

Autopsy studies of children who had died in accidents or by homicide have shown that $50 \%$ of 2-15 year old children have fatty streaks in the coronary arteries, and all of them have fatty streaks in the aorta. ${ }^{35}$ As the extent of these lesions was related to body mass index, blood pressure, and blood lipids, an improvement in the cardiovascular risk score by a lifestyle intervention early in life focusing on several essential health outcomes may help to slow the occurrence of these atherosclerotic changes.

\section{Strengths and limitations}

This study contributes a practical way of successfully implementing a physical activity programme in public schools to reduce the extensive health burden of childhood obesity. It shows that primary prevention in school by a multi-component physical activity curriculum including daily physical education based on a structured curriculum, short activity breaks, and physical activity homework, can improve aerobic fitness and decrease body fat and possibly cardiovascular risk. The favourable outcome of this pure physical activity intervention is even more encouraging considering the high participation rate and the use of precise methods. We used skinfold measurements to define the level of obesity in addition to the more imprecise measure of body mass index, and we assessed aerobic fitness, all important cardiovascular risk factors, and physical activity by objective means. The success of this study, in contrast to other well designed randomised controlled trials, ${ }^{1327}$ probably lies in the mandatory structure of the intervention by changing the school environment. ${ }^{36}$ Importantly, the children and teachers enjoyed the intervention, which guaranteed compliance, and it was sufficiently intense, of adequate duration, ${ }^{37}$ and included expert physical education teachers. ${ }^{38}$ On the basis of the accelerometer data, the in-school part of the intervention - that is, structuring of the existent three physical education lessons and adding two additional lessons and activity breakswas almost entirely responsible for this difference.

The level of adherence to the intervention outside school (physical activity homework) was insufficient, which is a limitation of this study. Nevertheless, the qualitatively and quantitatively improved physical education resulted in higher levels of total and moderate-vigorous physical activity in school as well as over the whole day, which was sufficient to improve aerobic fitness. ${ }^{39}$ This emphasises the importance of an 


\section{WHAT IS ALREADY KNOWN ON THIS TOPIC}

Obesity, physical inactivity, and low aerobic fitness in children are related and represent major public health concerns

All the above factors are associated with increased cardiovascular risk factors

Little is known about optimal characteristics of school based physical activity interventions to effectively prevent obesity and improve physical activity and fitness in school aged children

\section{WHAT THIS STUDY ADDS}

A multi-component physical activity intervention during one school year had beneficial effects on physical activity, aerobic fitness, and adiposity and may thus reduce cardiovascular risk

This success was probably due to attractiveness of the programme for children and teachers, its intensity, the use of expert physical education teachers, and integration into the regular school curriculum children and $70 \%$ of the teachers liked the programme and wished that it would continue is also reassuring. The multi-component and systemic physical activity approach, which included a variety of strategies to enhance physical activity, may have reached more children by broadening the levels of the intervention and the spectrum of activities. All these components might encourage children to increase activity levels in the future by increasing joy, fitness, and motor skills that further enhance physical activity with potential beneficial effects on body composition and cardiovascular risk. Although we know that our programme was successful when applied over the period of one academic year, we do not know whether the effects could be sustained. Future research should include intervention programmes over several years and long term follow-up to define the ideal content, setting, and duration of preventive interventions, as well as assessment of costs to define the cost effectiveness of such interventions.

\section{Conclusions}

A school based, multi-component physical activity intervention including compulsory elements improved physical activity and fitness and reduced adiposity in children. Implementation of such a programme may help to improve the health and fitness of children and also to improve health later in life by reducing cardiovascular and other diseases.

We thank all children, teachers, and parents for taking part in the study. We are grateful to Tom Hornbein for his editorial guidance.

Contributors: All authors had full access to the data and can take responsibility for the integrity of the data and the accuracy of the data analyses. SK, LZ, JPP, UM, and HH were responsible for the study concept and design and the acquisition of data. SK, JP, TH, HH, and CS were responsible for analysing and interpreting data. SK and JP drafted the manuscript. All authors critically revised the manuscript for important intellectual content. Funding was obtained by SK and LZ. SK and JP are the guarantors.

Funding: This study was funded by the Swiss Federal Office of Sports (grant number SWI05-013), the Swiss National Science Foundation (grant number PMPDB-114401), and the Diabetes Foundation of the Region of Basel. The funding sources had no role in the design and conduct of the study or in the collection, management, analysis, and interpretation of the data.

Competing interests: None declared.

Ethical approval: The study was approved by the ethics committees of the University of Basel and the ETH of Zürich, as well as by the Cantonal Ethical Committee of Aargau, Switzerland. All participating children and their parents gave informed consent.

Data sharing: No additional data available.

1 Kipping RR, Jago R, Lawlor DA. Obesity in children. Part 1: epidemiology, measurement, risk factors, and screening. BMJ 2008;337:a1824.

2 Ogden CL, Carroll MD, Curtin LR, McDowell MA, Tabak CJ, Flegal KM. Prevalence of overweight and obesity in the United States, 19992004. JAMA 2006;295:1549-55.

3 Weiss R, Dziura J, Burgert TS, Tamborlane WV, Taksali SE, Yeckel CW, et al. Obesity and the metabolic syndrome in children and adolescents. N Engl J Med 2004;350:2362-74.

4 Daniels SR, Arnett DK, Eckel RH, Gidding SS, Hayman LL, Kumanyika S, et al. Overweight in children and adolescents: pathophysiology, consequences, prevention, and treatment. Circulation 2005;111:1999-2012.

5 Olshansky SJ, Passaro DJ, Hershow RC, Layden J, Carnes BA, Brody J, et al. A potential decline in life expectancy in the United States in the 21st century. N Engl J Med 2005;352:1138-45. 
6 Must A, Tybor DJ. Physical activity and sedentary behavior: a review of longitudinal studies of weight and adiposity in youth. Int J Obes (Lond) 2005;29(suppl 2):84-96S.

7 Hu FB, Willett WC, Li T, Stampfer MJ, Colditz GA, Manson JE. Adiposity as compared with physical activity in predicting mortality among women. N Engl J Med 2004;351:2694-703.

8 Andersen LB, Harro M, Sardinha LB, Froberg K, Ekelund U, Brage S, et al. Physical activity and clustered cardiovascular risk in children: a cross-sectional study (the European Youth Heart Study). Lancet 2006;368:299-304.

9 Brage S, Wedderkopp N, Ekelund U, Franks PW, Wareham NJ, Andersen LB, et al. Features of the metabolic syndrome are associated with objectively measured physical activity and fitness in Danish children: the European Youth Heart Study (EYHS). Diabetes Care 2004;27:2141-8.

10 Singh AS, Mulder C, Twisk JW, van Mechelen W, Chinapaw MJ. Tracking of childhood overweight into adulthood: a systematic review of the literature. Obes Rev 2008;9:474-88.

11 Bao W, Srinivasan SR, Wattigney WA, Berenson GS. Persistence of multiple cardiovascular risk clustering related to syndrome $X$ from childhood to young adulthood: the Bogalusa Heart Study. Arch Intern Med 1994;154:1842-7.

12 Van Sluijs EM, McMinn AM, Griffin SJ. Effectiveness of interventions to promote physical activity in children and adolescents: systematic review of controlled trials. BMJ 2007;335:703.

13 Summerbell C, Waters E, Edmunds L, Kelly S, Brown T, Campbell K. Interventions for preventing obesity in children. Cochrane Database Syst Rev 2002;(2):CD001871.

14 Kipping RR, Jago R, Lawlor DA. Obesity in children. Part 2: prevention and management. BMJ 2008;337:a1848.

15 Zahner L, Puder JJ, Roth R, Schmid M, Guldimann R, Puhse U, et al. A school-based physical activity program to improve health and fitness in children aged 6-13 years ("Kinder-Sportstudie KISS"): study design of a randomized controlled trial [ISRCTN15360785]. BMC Public Health 2006;6:147.

16 Egger G, Swinburn B. An "ecological" approach to the obesity pandemic. BMJ 1997;315:477-80.

17 Prader A, Largo RH, Molinari L, Issler C. Physical growth of Swiss children from birth to 20 years of age: first Zurich longitudinal study of growth and development. Helv Paediatr Acta Suppl 1989;52:1-125.

18 Lohman TG, Roche AF, Martorell R. Anthropometric standardization reference material. Human Kinetics Books, 1988.

19 Leger LA, Mercier D, Gadoury C, Lambert J. The multistage 20 metre shuttle run test for aerobic fitness. J Sports Sci 1988;6:93-101.

20 Freedson P, Pober D, Janz KF. Calibration of accelerometer output for children. Med Sci Sports Exerc 2005;37:523-30S.

21 Moses S, Meyer U, Puder J, Roth R, Zahner L, Kriemler S. Das Bewegungsverhalten von Primarschulkindern in der Schweiz. Schweiz Zt Sportmed Sporttraum 2007;55:62-8.

22 Landgraf JM, Maunsell E, Speechley KN, Bullinger M, Campbell S, Abetz L, et al. Canadian-French, German and UK versions of the child health questionnaire: methodology and preliminary item scaling results. Qual Life Res 1998;7:433-45.

23 National High Blood Pressure Education Program Working Group on High Blood Pressure in Children and Adolescents. The fourth report on the diagnosis, evaluation, and treatment of high blood pressure in children and adolescents. Pediatrics 2004;114:555-76.

24 Eisenmann JC. On the use of a continuous metabolic syndrome score in pediatric research. Cardiovasc Diabetol 2008;7:17.

25 Woringer V, Schutz Y. [Obesity in Switzerland: body mass index (BM) percentiles of a child and adolescent population born in 1980 in Lausanne and in comparison with Swiss norms (1955)]. Soz Praventivmed 2003;48:121-32.

26 Fredriks AM, van Buuren S, Fekkes M, Verloove-Vanhorick SP, Wit JM Are age references for waist circumference, hip circumference and waist-hip ratio in Dutch children useful in clinical practice? Eur J Pediatr 2005;164:216-22.

27 Kamath CC, Vickers KS, Ehrlich A, McGovern L, Johnson J, Singhal V, et al. Clinical review: behavioral interventions to prevent childhood obesity: a systematic review and metaanalyses of randomized trials. J Clin Endocrinol Metab 2008;93:4606-15.

28 Robinson TN. Reducing children's television viewing to prevent obesity: a randomized controlled trial. JAMA 1999;282:1561-7.

29 Baker JL, Olsen LW, Sorensen TI. Childhood body-mass index and the risk of coronary heart disease in adulthood. $N$ Engl J Med 2007;357:2329-37.

30 Must A, Jaques PF, Dallal GE, Bajema CJ, Dietz WH. Long-term morbidity and mortality of overweight adolescents: a follow up of the Harvard Growth Study of 1922-1935. N Engl J Med 1992;327:1350-5.

31 Tomkinson GR, Leger LA, Olds TS, Cazorla G. Secular trends in the performance of children and adolescents (1980-2000): an analysis of 55 studies of the $20 \mathrm{~m}$ shuttle run test in 11 countries. Sports Med 2003;33:285-300.

32 Manios Y, Kafatos A, Mamalakis G. The effects of a health education intervention initiated at first grade over a 3 year period: physical activity and fitness indices. Health Educ Res 1998;13:593-606.

33 Freedman DS, Kahn HS, Mei Z, Grummer-Strawn LM, Dietz WH, Srinivasan SR, et al. Relation of body mass index and waist-to-height ratio to cardiovascular disease risk factors in children and adolescents: the Bogalusa Heart Study. Am J Clin Nutr 2007;86:33-40

34 Rose G. Rose's strategy of preventive medicine. 2nd ed. Oxford University Press, 2008.

35 Berenson GS, Srinivasan SR, Bao W, Newman WP 3rd, Tracy RE, Wattigney WA. Association between multiple cardiovascular risk factors and atherosclerosis in children and young adults: the Bogalusa Heart Study. N Engl J Med 1998;338:1650-6.

36 Connelly JB, Duaso MJ, Butler G. A systematic review of controlled trials of interventions to prevent childhood obesity and overweight: realistic synthesis of the evidence. Public Health 2007;121:510-7.

37 Prochaska JO, Velicer WF. The transtheoretical model of health behavior change. Am J Health Promot 1997;12:38-48.

38 McKenzie TL, Sallis JF, Kolody B, Faucette FN. Long-term effects of a physical education curriculum and staff development program: SPARK. Res Q Exerc Sport 1997;68:280-91.

39 Luepker RV, Perry CL, McKinlay SM, Nader PR, Parcel GS, Stone El, et al. Outcomes of a field trial to improve children's dietary patterns and physical activity: the Child and Adolescent Trial for Cardiovascular Health. JAMA 1996;275:768-76.

Accepted: 15 December 2009 